\title{
Expression of CXCL12 and its receptor CXCR4 in patients with adenomyosis
}

\author{
JUAN LI, GEPING YIN, MING CHEN, SHUJUN YANG, AIFANG WU, JING LIANG and ZHENG YUAN \\ Department of Obstetrics and Gynecology, Jinan Military General Hospital, Jinan, Shandong 250031, P.R. China
}

Received September 11, 2015; Accepted December 9, 2016

DOI: $10.3892 / 01.2017 .5762$

\begin{abstract}
The aim of the present study was to investigate the role of chemokine (C-X-C motif) ligand 12 (CXCL12) and its receptor, chemokine $(\mathrm{C}-\mathrm{X}-\mathrm{C}$ motif) receptor $4(\mathrm{CXCR} 4)$ in the pathogenesis of adenomyosis (AD). Immunohistochemistry and reverse transcription-quantitative polymerase chain reaction analysis were used to measure the protein and mRNA expression of CXCL12 and CXCR4 in eutopic endometrial and ectopic foci tissue samples. Samples from a total of 36 patients with AD (study group) were compared with endometrial tissue samples from 33 patients who underwent uterine fibroids surgery (control group) during the same period. All data are presented as the mean \pm standard deviation and were analyzed with SPSS software (version 16.0). Analysis of variance was used for between group analysis and pairwise comparison was performed using Fisher's least significant difference post hoc test. The results of the present study revealed that CXCL12 and CXCR4 protein expression was significantly increased in ectopic foci tissue compared with eutopic endometrial tissue samples from patients with AD. CXCL12 and CXCR4 protein expression in ectopic foci and eutopic endometrial tissue samples were significantly increased compared with the control group ( $\mathrm{P}<0.05$ for between group comparisons). No significant differences were identified in CXCL12 and CXCR4 protein expression between the proliferative and secretory phases within each group. Furthermore, CXCL12 and CXCR4 mRNA expression was significantly increased in ectopic foci tissue and eutopic endometrial tissue compared with the control group $(\mathrm{P}<0.05$ for between group comparisons). CXCL12 mRNA expression was markedly increased in ectopic foci tissue compared with eutopic endometrial tissue of patients with AD. The expression of CXCR4 mRNA was significantly increased in eutopic endometrial tissue compared with ectopic foci tissue and the control group $(\mathrm{P}<0.05$ for between group comparisons). No significant differences
\end{abstract}

Correspondence to: Dr Geping Yin, Department of Obstetrics and Gynecology, Jinan Military General Hospital, 25 Shifan Road, Jinan, Shandong 250031, P.R. China

E-mail: ygpwyll1@hotmail.com

Key words: adenomyosis, CXCL12, CXCR4, pathogenesis were identified in CXCL12 and CXCR4 mRNA expression between proliferative and secretory phase within each group. In conclusion, CXCL12 and CXCR4 may induce the ectopia, and promote the spread and localized growth of endometrial cells in the development of AD.

\section{Introduction}

The incidence of adenomyosis (AD) has increased in recent years, affecting the quality of life and fertility of patients, and has become a popular topic of gynecological research $(1,2)$. Thus far, its etiology and pathogenesis remain unclear, despite several studies (3).

Among several hypotheses that attempt to explain the pathogenesis of $\mathrm{AD}$, the theory of endometrial damage is widely accepted. This theory states that endometrial cells invade the myometrium through the damaged endometrium and grow ectopically, subsequently leading to an adenomyotic lesion $(3,4)$. The incidence of pregnancy, delivery, abortion and intrauterine device use has been demonstrated to be increased in patients with AD compared with healthy controls, thus supporting the theory of endometrial damage $(4,5)$. Furthermore, surgeries, including cesarean sections and the removal of uterine fibroids, are considered pathogenic risk factors of AD (6). However, the mechanism by which endometrial cells invade the myometrium through the damaged endomembrane and proliferate ectopically remains unclear.

Chemokines regulate the movement of leukocytes during the inflammatory response. Chemokine ( $\mathrm{C}-\mathrm{X}-\mathrm{C}$ motif) ligand 12 (CXCL12), also known as stromal cell-derived factor 1, belongs to the CXC chemokine family. Chemokine (C-X-C motif) receptor 4 (CXCR4) is a specific receptor for CXCL12 (7-9), and binds with a high affinity to form the CXCL12/CXCR4 axis. The CXCL12/CXCR4 axis serves an important role in promoting tumor cell invasion and directed metastasis, and is associated with the progression and prognosis of cancer, such as bone metastasis in hepatocellular carcinoma (10-13). Although AD is a benign disease, the pathological progression, including cell adhesion, invasion, metastasis and recurrence, is similar to that in malignant tumors $(14,15)$. To the best of our knowledge, the concentrations of CXCL12 and CXCR4 in adenomyotic tissue have not yet been reported. In the present study, the expression levels of CXCL12 and CXCR4 in the ectopic foci and eutopic endometrium of patients with AD were investigated and compared 
with the expression in the endometrial tissue of patients with uterine fibroids, in order to investigate the role of CXCL12 and CXCR4 in the pathogenesis of AD.

\section{Patients and methods}

Patients. Patients who underwent a complete or partial hysterectomy, or a surgical excision at Jinan Military General Hospital (Jinan, China) between February 2011 and February 2012 were enrolled for the present study if their medical records were complete. The inclusion criteria were as follows: Pre-menopausal women with a diagnosis of AD or uterine fibroids confirmed through surgery and postoperative pathological analysis; and no involvement with antiestrogen and progesterone therapy in the month prior to surgery. The exclusion criteria included the following: Patients with other coexistent gynecological tumors, diabetes, hypertension or tumors of other systems; and steroid hormone therapy in the month prior to surgery. The study group consisted of $\mathrm{AD}$ patients who contributed ectopic foci and eutopic endometrium specimens, and the control group, which contained patients with uterine fibroids who contributed normal endometrium specimens.

A total of 69 patients were enrolled in the present study, all of whom lived in Shandong, China. In total, 36 were patients with AD (study group), with a mean age of $38.7 \pm 6.2$ years old (range, 27-51 years old). Among the patients with AD, 21 cases were in the endometrial proliferative phase and 15 cases were in the secretory phase. A total of 33 cases were patients with uterine fibroids (control group), with a mean age of $41.2 \pm 5.2$ years old (range, 32-50 years old), of which 18 cases were in the proliferative phase and 15 cases were in the secretory phase. There was no significant difference in the ages between the two groups.

Specimens. Eutopic endometrial specimens were collected during the preoperative diagnostic curettage and ectopic foci tissues were collected from the resected uterine lesion of patients with AD. Healthy endometrial specimens were collected during the diagnostic curettage from the removed uterus following uterine fibroids surgery, or during the removal of submucosal fibroids. For the immunohistochemistry tests, the specimens were fixed immediately in neutral formaldehyde solution for $24 \mathrm{~h}$. Samples for reverse transcription-quantitative polymerase chain reaction (RT-qPCR) were stored in liquid nitrogen and transferred to a $-80^{\circ} \mathrm{C}$ freezer. Written informed consent was obtained from all participants and the present study was approved by the Medical Ethics Research Committee of Jinan Military General Hospital.

Immunohistochemistry. The streptavidin peroxidase-conjugated method as previously described (16) was used to measure the expression of CXCL12 and CXCR4 protein. The formalin-fixed paraffin-embedded tissues were cut into $5-\mu \mathrm{m}$ thick sections. The sections were deparaffinized in xylene twice for 10 min each, rehydrated with a descending series of ethanol $(100,75$ and $50 \%)$ for $5 \mathrm{~min}$ each at $37^{\circ} \mathrm{C}$, and washed 3 times in phosphate-buffered saline (PBS). Sections were incubated in $50 \mu \mathrm{l}$ of $3 \%$ hydrogen peroxide at room temperature for $10 \mathrm{~min}$ and subsequently washed 3 times in
PBS. The specimens were placed in EDTA antigen retrieval solution (Shanghai Biyuntian Biological Technology Co., Ltd., Shanghai, China) for $3 \mathrm{~min}$ at $37^{\circ} \mathrm{C}$ and washed 3 times in PBS.

Each section was incubated at $4^{\circ} \mathrm{C}$ overnight with $50 \mu 1$, CXCL12 monoclonal primary antibody working solution (cat. no. M05; dilution, 1:200; Amyjet Scientific, Inc., Wuhan, China), mouse anti-human CXCR4 monoclonal primary antibody working solution (cat. no. ab10403; dilution, 1:200; Abcam, Cambridge, UK) and washed in PBS 3 times. Subsequently, sections were incubated at $37^{\circ} \mathrm{C}$ for $1 \mathrm{~h}$ with $50 \mu \mathrm{l}$ biotin-labeled goat anti-mouse secondary antibody working solution (cat. no. bs-0296G; dilution, 1:200; Beijing Boosen Biological Technology Co., Ltd. Beijing, China) and washed in PBS. Each section was stained with $50 \mu 1$ 3,3-diaminobenzidine for $10 \mathrm{~min}$, followed by a PBS wash, clear water rinse, hematoxylin counterstaining for $1 \mathrm{~min}$ and a second PBS wash. Subsequently, the sections were dehydrated with ethanol, cleared in xylene, mounted with neutral gum and observed under a light microscope. Positively-stained cells were defined as cells with brown granules in the cytoplasm. A total of 5 high-power fields (magnification, x200) were randomly selected to count by eye the percentage of positively stained cells in the vision field and the mean was calculated.

$R T-q P C R$ analysis of CXCL12 and CXCR4 mRNA. A 0.2-g tissue sample was cut from each specimen with sterile scissors and ground into a powder using a mortar pre-cooled with liquid nitrogen. Tissue samples were subsequently homogenized with $1 \mathrm{ml}$ RNAiso plus and total RNA was reverse transcribed into cDNA [cDNA volume of the master mix used: $1 \mu 1$, volume of primer: $1 \mu \mathrm{l}(10 \mu \mathrm{M} / \mu \mathrm{l})]$ using the PrimeScript ${ }^{\mathrm{TM}}$ RT Reagent kit (both Takara Biotechnology Co., Ltd., Dalian, China). The homogenate was transferred to a centrifuge tube, placed at room temperature for $5 \mathrm{~min}$ and centrifuged at $4^{\circ} \mathrm{C}, 12,000 \mathrm{xg}$ for $5 \mathrm{~min}$. The supernatant was transferred to a new centrifuge tube, incubated with $1 / 5$ volume of chloroform at $4^{\circ} \mathrm{C}$ for $5 \mathrm{~min}$ and centrifuged at $4^{\circ} \mathrm{C}, 12,000 \times \mathrm{g}$ for $15 \mathrm{~min}$. Subsequently, the supernatant was transferred to a new centrifuge tube, incubated at room temperature for 10 min with an equal amount of isopropanol and centrifuged at $4^{\circ} \mathrm{C}, 12,000 \mathrm{x} g$ for $10 \mathrm{~min}$. The supernatant was discarded, $1 \mathrm{ml} 75 \%$ ethanol was added and the suspension was centrifuged at $4^{\circ} \mathrm{C}, 12,000 \times \mathrm{g}$ for $10 \mathrm{~min}$. Following the removal of ethanol, $0.5 \mathrm{ml}$ RNase-free water was added to dissolve the RNA. 1.25\% agarose gel electrophoresis analysis using ethidium bromide was performed to confirm the presence of CXCL12 and CXCR4 mRNA in the three groups.

Subsequent qPCR was performed using PrimeScript RT reagent kit (Takara Biotechnology Co., Ltd., Dalian, China) and a LightCycler ${ }^{\circledast} 480$ Real-Time PCR system (Roche Diagnostics GmbH, Mannheim, Germany). qPCR thermocycling conditions consisted of a pre-denaturation step at $95^{\circ} \mathrm{C}$ for $30 \mathrm{sec}$, followed by $40 \mathrm{PCR}$ cycles of $95^{\circ} \mathrm{C}$ for $5 \mathrm{sec}$ and $60^{\circ} \mathrm{C}$ for $30 \mathrm{sec}$. GAPDH (425 bp) was used as an internal reference with the following primers: Forward, 5-ACCACAGTCCAT GCCATCAC-3 and reverse, 5-TCCACCACCCTGTTGCTG TA-3. The primer sequences were determined based on human mRNA genome sequences provided by GenBank (National Center for Biotechnology Information; Bethesda, MD, USA). 


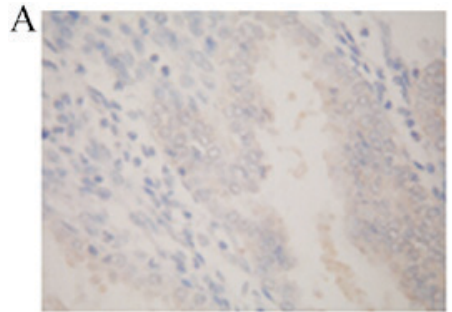

(x400)

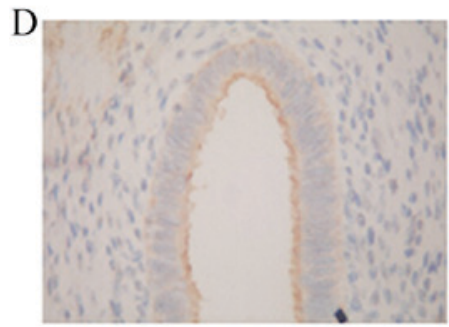

$(x 400)$

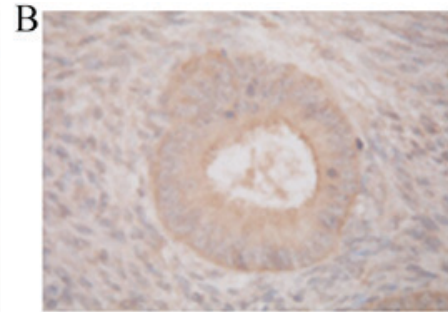

(x400)

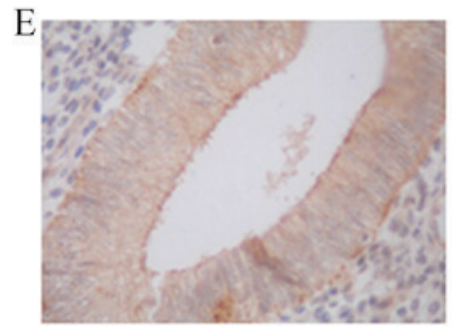

$(\mathbf{x} 400)$

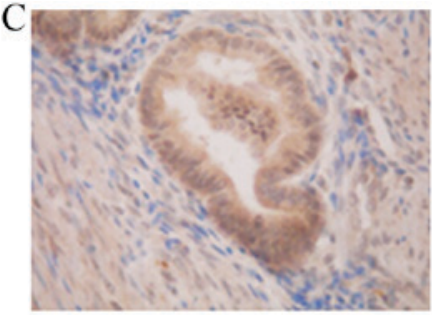

$(\mathrm{x} 400)$

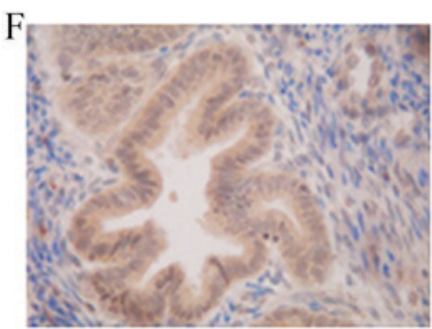

$(\times 400)$

Figure 1. Representative images of immunohistochemical staining of CXCL12 and CXCR4 protein expression in different tissues. CXCL12 expression in (A) healthy endometrial tissue, (B) AD eutopic endometrial tissue and (C) AD ectopic foci tissue. CXCR4 expression in (D) healthy endometrial tissue, (E) AD eutopic endometrial tissue and (F) AD ectopic foci tissue. AD, adenomyosis; CXCL12, chemokine (C-X-C motif) ligand 12; CXCR4, chemokine (C-X-C motif) receptor 4 .

The following primer sequences were used: CXCL12 forward, 5-GAGCCAACGTCAAGCATCTCAA-3 and reverse, 5-TTT AGCTTCGGGTCAATGCACA-3; CXCR4 forward, 5-CTC CAGTAGCCACCGCATCT-3 and reverse, 5-TCCTCGGTG TAGTTATCTGAAGTGT-3. Primers were obtained from Takara Biotechnology Co., Ltd. The qPCR results are relative quantifications of gene expression and calculated using $\Delta \mathrm{Cq}=\mathrm{Cq}_{\text {target gene }}-\mathrm{Cq}_{\text {reference gene }}(17)$. The $\Delta \mathrm{Cq}$ value was used in the statistical analysis, where an increased $\Delta \mathrm{Cq}$ value indicated a decreased expression of the target gene. Experiments were repeated three times.

Statistical analysis. All data are presented as the mean \pm standard deviation. Data were analyzed with SPSS software (version 16.0; SPSS, Inc., Chicago, IL, USA). Two-way analysis of variance was used for comparisons between groups, and pairwise comparison was performed using Fisher's least significant difference post hoc test. $\mathrm{P}<0.05$ was considered to indicate a statistically significant difference.

\section{Results}

Expression of CXCL12 and CXCR4 protein. Representative images of immunohistochemical staining of CXCL12 and CXCR4 protein in ectopic foci, eutopic endometrial and healthy endometrial tissue samples are illustrated in Fig. 1. Expression of CXCL12 and CXCR4 protein was significantly increased in ectopic foci tissue $(9.78 \pm 2.02$ and $7.44 \pm 3.49)$ compared with eutopic endometrial tissue $(4.33 \pm 2.12$ and 4.06 \pm 2.83$)$ and control endometrial tissue $(3.06 \pm 1.82$ and $2.58 \pm 2.14)$, respectively $(\mathrm{P}<0.05)$ (Fig. 2). Furthermore, CXCL12 $(\mathrm{P}=0.009)$ and CXCR4 $(\mathrm{P}=0.036)$ protein expression in eutopic endometrial tissue were significantly increased compared with the control group. Within each group, no significant differences in CXCL12 and CXCR4 protein expression were identified between proliferative and secretory phases. A positive correlation was identified between CXCL12 and CXCR4 protein expression in eutopic endometrial and ectopic foci tissues (both $\mathrm{r}=0.78 ; \mathrm{P}<0.05$; Fig. 2).

Expression of CXCL12 and CXCR4 $m R N A$. Gel electrophoresis results from RT-PCR analysis of CXCR4 and CXCL12 mRNA are illustrated in Fig. 3. The qPCR results, as indicated by $\triangle \mathrm{Cq}$ (lower $\Delta \mathrm{Cq}$ equaling higher gene expression), demonstrated that CXCL12 and CXCR4 mRNA expression was significantly increased, although the error bars are notably overlapping for CXCL12 and CXCR4 in ectopic foci tissue $(1.26 \pm 0.76$ and $4.61 \pm 1.47)$ and eutopic endometrial tissue $(1.85 \pm 1.30$ and $3.58 \pm 1.51)$ compared with healthy endometrial tissue

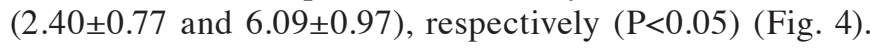
Although the error bars are notably overlapping for CXCR4, CXCL12 mRNA expression was marked and was decreased in eutopic endometrial tissue compared with ectopic foci tissue. However, CXCR4 mRNA expression was significantly increased in eutopic endometrial tissue compared with ectopic foci tissue. Within each group, no significant differences in CXCL12 and CXCR4 mRNA expression were identified between proliferative and secretory phases ( $\mathrm{P}>0.05)$ (Fig. 4).

\section{Discussion}

In the present study, it was demonstrated that the total CXCL12 and CXCR4 protein expression from proliferative and secretory phases, in ectopic foci and eutopic endometrial tissue samples were significantly increased compared with that in healthy endometrial tissue. Furthermore, the total CXCR4 mRNA expression in eutopic endometrial tissue was significantly decreased compared with that in ectopic foci tissue. No significant differences were identified between the proliferation and secretory phases in all groups.

The results of the present study suggest that CXCL12 and CXCR4 are involved in the pathogenesis of AD. The 

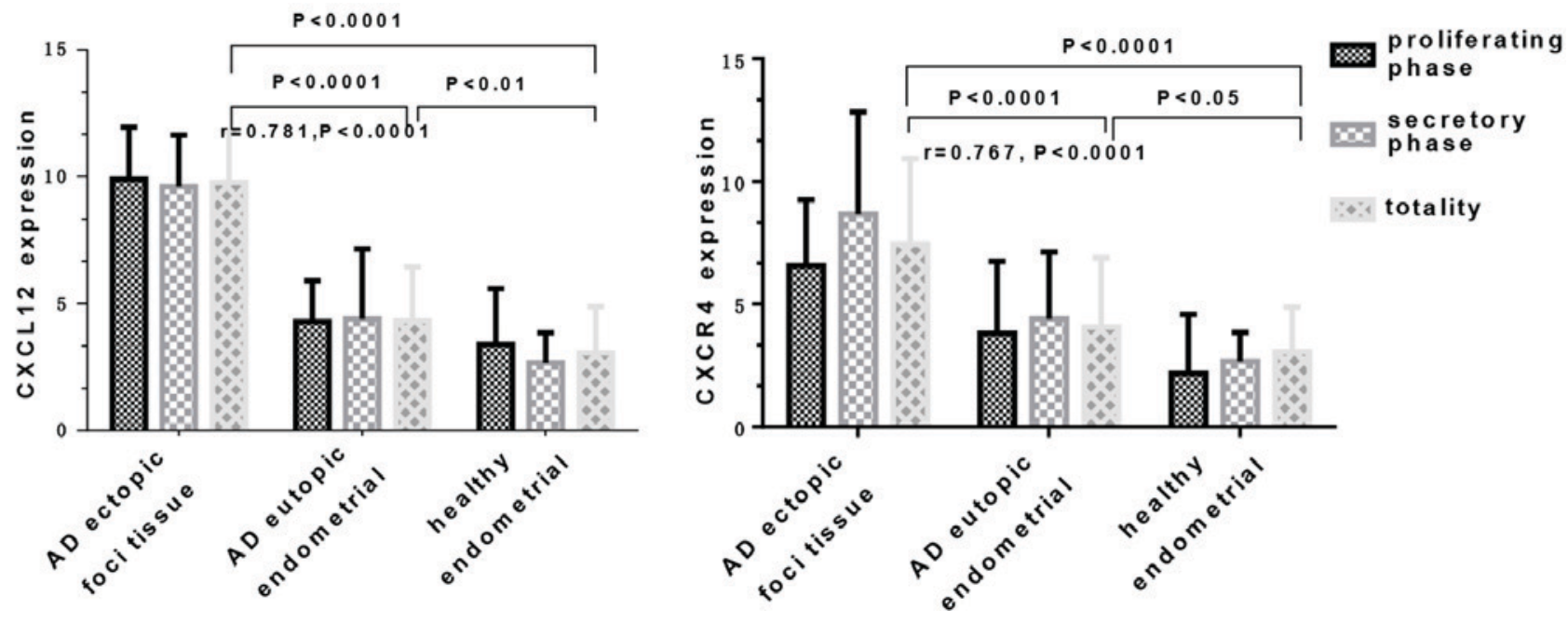

Figure 2. CXCL12 and CXCR4 protein expression in different tissues. AD, adenomyosis; CXCL12, chemokine (C-X-C motif) ligand 12; CXCR4, chemokine (C-X-C motif) receptor 4.

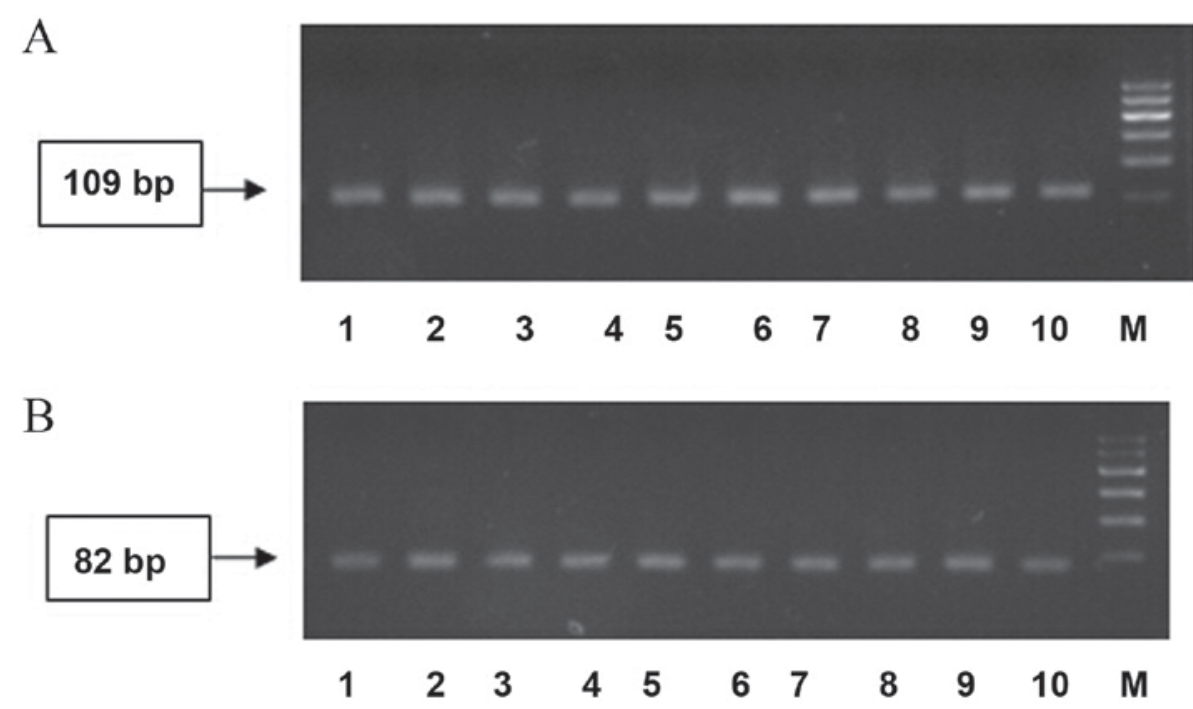

Figure 3. Gel electrophoresis of reverse transcription-polymerase chain reaction amplification products. mRNA expression of (A) chemokine (C-X-C motif) ligand 12 and (B) chemokine (C-X-C motif) receptor 4. Lanes: M, marker; 1, eutopic endometrial tissue (secretory phase); 2, eutopic endometrial tissue (proliferative phase); 3 , healthy endometrial tissue (secretory phase); 4, healthy endometrial tissue (proliferative phase); 5 and 6 , tissue surrounding the lesions; 7 and 8 , ectopic foci tissue; 9 and 10, muscular layer in healthy control.
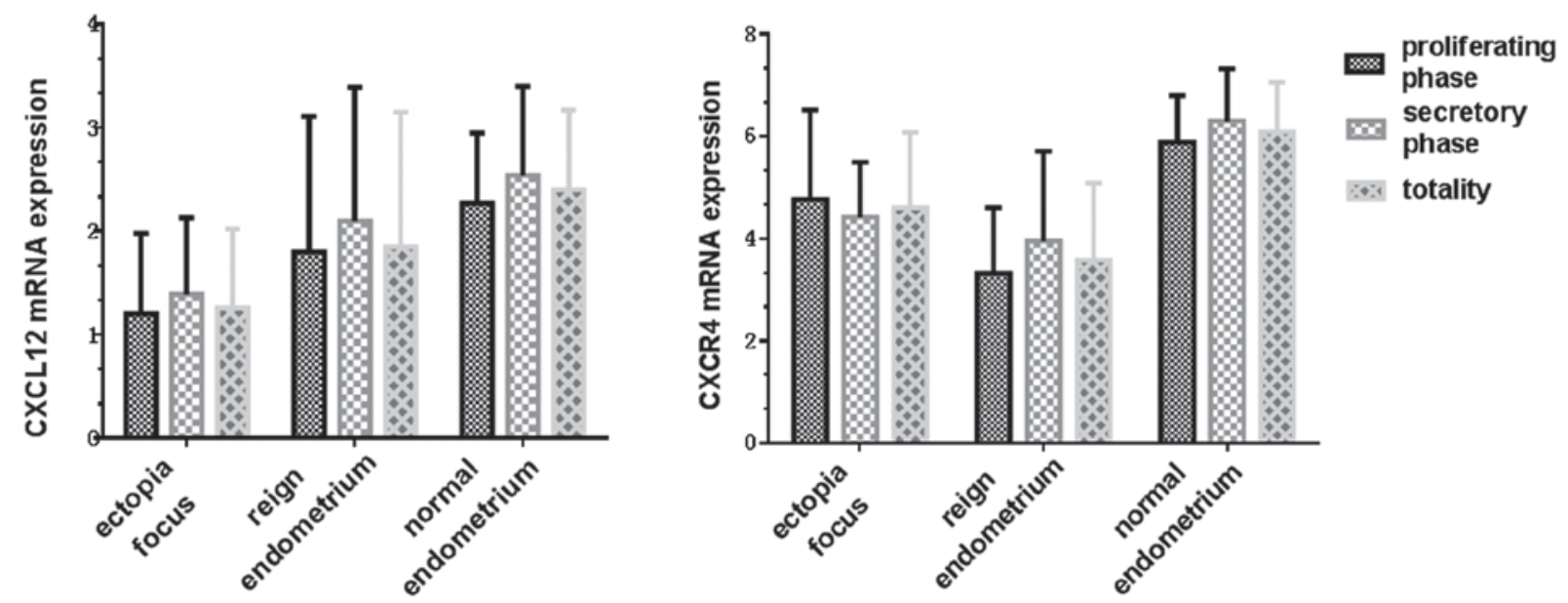

Figure 4. CXCL12 mRNA and CXCR4 mRNA expression in different tissues. Increased mRNA expression is indicated by a decreased $\triangle$ Cq value. CXCL12, chemokine (C-X-C motif) ligand 12; CXCR4, chemokine (C-X-C motif) receptor 4. 
underlying mechanism may involve an abnormal loci of the CXCL12 and CXCR4 genes. This could induce increased expression of CXCL12 protein in patients with AD (18), and through the interaction with CXCR4 in eutopic endometrium (19), activate an unknown signaling pathway to induce endometrial cell proliferation, the deformation of endometrial cells and the degradation of the extracellular matrix, subsequently producing the conditions required for the development of ectopic endometrial cells. Furthermore, the interactions between the cells and the local microenvironment promote the synthesis and release of CXCL12 and CXCR4, amplifying the effect. In addition, due to the interaction between CXCL12 and CXCR4, ectopic endometrial cells migrate to the myometrial layer according to the gradient of their expression. Subsequently, ectopic cells produce endometriotic lesions through the induction of cell proliferation and angiogenesis.

To the best of our knowledge, the change of CXCR4 expression in endometrial tissue and the expression of CXCL12 and CXCR4 in AD tissues have not yet been reported. A results of a study performed by Laird et al (20) demonstrated that CXCL12 expression in the healthy endometrial tissue of women of childbearing age was independent of the menstrual cycle. These results suggest that CXCL12 and CXCR4 expression are not affected by the fluctuation of estrogen and progesterone levels; however, further studies are warranted to confirm this. Huang et al (21) revealed that CXCL12, through interaction with CXCR4, can induce the phosphorylation of mitogen-activated protein kinase, extracellular signal-regulated kinase, nuclear factor-I and nuclear factor $\mathrm{NF}-\kappa \mathrm{B}$, leading to the metastasis of osteosarcoma cells. Furthermore, Gao et al (22) and Lu et al (23) reported that the CXCL12/CXCR4 axis serves an important role in the invasion and metastasis of cancer cells through similar signaling pathways. The CXCL12/CXCR4 axis can directly stimulate the growth of cancer cells, induce the degradation of the extracellular matrix and produce the conditions required for cancer cell metastasis $(24,25)$.

The results of a study on breast cancer performed by Wendel et al (26) demonstrated that CXCL12 induces morphological changes and chemotaxis. Mo et al (27) reported that, by activating cyclin D1, phosphoinositide 3-kinase and $\beta$-cyclic peptides, CXCL12 and CXCR4 promote the growth of cancer cells in malignant peripheral nerve sheath tumors in patients with type I neurofibromatosis, and that inhibition of CXCR4 activity may control cancer cell growth. These studies suggested that CXCL12, by interacting with CXCR4, activates certain signaling pathways and causes cell deformation, and thus leads to the movement and migration of these cells. We hypothesize that in the eutopic endometrium of patients with AD, increased CXCL12 and CXCR4 expression may activate signaling transduction pathways, stimulate the proliferation and deformation of endometrial cells, prompt the degradation of the extracellular matrix, and promote the migration of ectopic cells to the myometrium. Thus, by inhibiting CXCR4 activity, these signaling transduction pathways may be blocked, preventing the migration of ectopic endometrial cells to the myometrium.

The results of the present study revealed that CXCL12 mRNA expression was increased in eutopic endometrium compared with ectopic foci tissues, whereas CXCR4 mRNA expression markedly decreased compared with that in ectopic foci tissue in patients with AD. In the common organs affected by metastatic pancreatic cancer, such as the liver and lungs, increased expression of CXCL12 has been demonstrated, suggesting that the CXCL12/CXCR4 axis serves a role in the organ-specific metastasis of cancer cells (28). The results of a previous study demonstrated that cancer cells metastasize along the concentration gradient of CXCL12 in salivary gland carcinoma (29). CXCR4 is essential in this process, and the application of CXCR4 antagonist ADM3100 could interrupt the metastasis of cancer cells. CXCL12/CXCR4 has been revealed to serve an essential role in tumor cell chemotaxis, proliferation, invasion, angiogenesis, and in particular, organ-specific tumor metastasis (29). The overexpression of CXCR4 in tumor cells and the increased expression of CXCL12 in the cells of target organs facilitate tumor metastasis through the CXCL12/CXCR4 axis $(30,31)$. We hypothesize that in AD, the changes and differences in CXCL12 and CXCR4 expression between the eutopic endometrium andectopicfociare associated with the migration, diffusion and focal growth of ectopic cells in the myometrium. Under the influence of the microenvironment in the myometrium, ectopic endometrial cells synthesize and release CXCL12 and CXCR4. Increased CXCL12 expression subsequently induces the migration of endometrial cells to the myometrium, aided by the increased CXCR4 expression in the eutopic endometrium.

In conclusion, the results of the present study suggest that CXCL12 and CXCR4 are involved in the pathogenesis of AD. Understanding the specific mechanism of their action may provide useful information for the prevention of $\mathrm{AD}$. The main limitations of the study are that it is based on tissue samples of patients from a single medical center, and the patient cohort was relatively small. Additional studies are necessary to understand the specific mechanism of the involvement of CXCL12 and CXCR4 in the pathogenesis of AD.

\section{References}

1. Wood C: Adenomyosis: Difficult to diagnose, and difficult to treat. Diagn Ther Endosc 7: 89-95, 2001

2. Fourquet J, Gao X, Zavala D, Orengo JC, Abac S, Ruiz A, Laboy J and Flores I: Patients' report on how endometriosis affects health, work, and daily life. Fertil Steril 93: 2424-2428, 2010.

3. Bergeron C, Amant F and Ferenczy A: Pathology and physiopathology of adenomyosis. Best Pract Res Clin Obstet Gynaecol 20: 511-521, 2006.

4. Shrestha A: Risk factors for adenomyosis. J Nepal Health Res Counc 10: 229-233, 2012.

5. Tomassetti C, Meuleman C, Timmerman D and D'Hooghe T: Adenomyosis and subfertility: Evidence of association and causation. Semin Reprod Med 31: 101-108, 2013.

6. Nepomnachhikh LM, Lushnikova EL, Pekarev OG, Lushnikova AK and Nikitenko EV: Pathomorphological analysis of internal endometriosis. Bull Exp Biol Med 153: 109-113, 2012.

7. Yu L, Cecil J, Peng SB, Schrementi J, Kovacevic S, Paul D, Su EW and Wang J: Identification and expression of novel isoforms of human stromal cell-derived factor 1. Gene 374: 174-179, 2006.

8. Mirian M, Zarghi A, Sadeghi S, Tabaraki P, Tavallaee M, Dadrass O and Sadeghi-Aliabadi H: Synthesis and cytotoxic evaluation of some novel sulfonamidederivativesagainst a few human cancer cells. Iran J Pharm Res 10: 741-748, 2011.

9. Mokhtari S, Mosaddegh M, Hamzeloo Moghadam M, Soleymani Z, Ghafari S and Kobarfard F: Synthesis and cytotoxic evaluation of novel 3-substituted derivatives of 2-indolinone. Iran J Pharm Res 11: 411-421, 2012.

10. Furusato B, Mohamed A, Uhlón M and Rhim JS: CXCR4 and cancer. Pathol Int 60: 497-505, 2010. 
11. Salvatore P, Pagliarulo C, Colicchio $R$ and Napoli $C$ CXCR4-CXCL12-dependent inflammatory network and endothelial progenitors. Curr Med Chem 17: 3019-3029, 2010

12. Xiang ZL, Zeng ZC, Fan J, Wu WZ, He J, Zeng HY and Tang ZY: A clinicopathological model to predict bone metastasis in hepatocellular carcinoma. J Cancer Res Clin Oncol 137: 1791-1797, 2011.

13. Zhu Q, Han X, Peng J, Qin H and Wang Y: The role of CXC chemokines and their receptors in the progression and treatment of tumors. J Mol Histol 43: 699-713, 2012.

14. Leyendecker G, Wildt L and Mall G: The pathophysiology of endometriosis and adenomyosis: Tissue injury and repair. Arch Gynecol Obstet 280: 529-538, 2009.

15. Wang Q, Wang L, Shao J, Wang Y, Jin LP, Li DJ and Li MQ: L-22 enhances the invasiveness of endometrial stromal cells of adenomyosis in an autocrine manner. Int J Clin Exp Pathol 7: 5762-5771, 2014.

16. AN J, Yao G, Zhou G, Wu X, Lin T, Ai C and Li Q: Application of microwave immunohistochemistry streptavidin peroxdase conjugataed method on morphologic study of borrelia burgdorferi in haemaphysalis longicornis. Chin J Vec Biol Contr 2:122-123, 2003 (In Chinese).

17. Livak KJ and Schmittgen TD: Analysis of relative gene expression data using real-time quantitative PCR and the 2(-Delta Delta C(T)) method. Methods 25: 402-408, 2001.

18. Kryczek I, Wei S, Keller E, Liu R and Zou W: Stroma-derived factor (SDF-1/CXCL12) and human tumor pathogenesis. Am J Physiol Cell Physiol 292: C987-C995, 2007.

19. Chu H, Zhou H, Liu Y, Liu X, Hu Y and Zhang J: Functional expression of $\mathrm{CXC}$ chemokine recepter- 4 mediates the secretion of matrix metalloproteinases from mouse hepatocarcinoma cell lines with different lymphatic metastasis ability. Int J Biochem Cell Biol 39: 197-205, 2007.

20. Laird SM, Widdowson R, El-Sheikhi M, Hall AJ and Li TC: Expression of CXCL12 and CXCR4 in human endometrium; effects of CXCL12 on MMP production by human endometrial cells. Hum Reprod 26: 1144-1152, 2011.

21. Huang CY, Lee CY, Chen MY, Yang WH, Chen YH, Chang CH, Hsu HC, Fong YC and Tang CH: Stromal cell-derived factor-1/CXCR4 enhanced motility of human osteosarcoma cells involves MEK1/2, ERK and NF-kappaB-dependent pathways. J Cell Physiol 221: 204-212, 2009.

22. Gao H, Priebe W, Glod J and Banerjee D: Activation of signal transducers and activators of transcription 3 and focal adhesion kinase by stromal cell-derived factor 1 is required for migration of human mesenchymal stem cells in response to tumor cell-conditioned medium. Stem Cells 27: 857-865, 2009.
23. Lu DY, Tang $\mathrm{CH}$, Yeh WL, Wong KL, Lin CP, Chen $\mathrm{YH}$, Lai $\mathrm{CH}$, Chen YF, Leung YM and Fu WM: SDF-1alpha up-regulates interleukin-6 through CXCR4, PI3K/Akt, ERK and NF-kappaB-dependent pathway in microglia. Eur J Pharmacol 613: 146-154, 2009.

24. Rubie C, Frick VO, Ghadjar P, Wagner M, Justinger C, Faust SK, Vicinus B, Graber S, Kollmar O and Schilling MK: CXC receptor-4 mRNA silencing abrogates CXCL12-induced migration of colorectal cancer cells. J Transl Med 9: 22, 2011.

25. Wald O, Izhar U, Amir G, Kirshberg S, Shlomai Z, Zamir G, Peled A and Shapira OM: Interaction between neoplastic cells and cancer-associated fibroblasts through the CXCL12/CXCR4 axis: Role in non-small cell lung cancer tumor proliferation. J Thorac Cardiovasc Surg 141: 1503-1512, 2011.

26. Wendel C, Hemping-Bovenkerk A, Krasnyanska J, Mees ST, Kochetkova M, Stoeppeler S and Haier J: CXCR4/CXCL12 participate in extravasation of metastasizing breast cancer cells within the liver in a rat model. PLoS One 7: e30046, 2012.

27. Mo W, Chen J, Patel A, Zhang L, Chau V, Li Y, Cho W, Lim K, $\mathrm{Xu} \mathrm{J}$ and Lazar AJ: CXCR4/CXCL12 mediate autocrine cellcycle progression in NF1-associated malignant peripheral nerve sheath tumors. Cell 152: 1077-1090, 2013.

28. Muller A, Homey B, Soto H, Ge N, Catron D, Buchanan ME, McClanahan T, Murphy E, Yuan W and Wagner SN: Involvement of chemokine receptors in breast cancer metastasis. Nature 410: 50-56, 2001.

29. Uchida D, Kuribayashi N, Kinouchi M, Ohe G, Tamatani T, Nagai $\mathrm{H}$ and Miyamoto Y: Expression and function of CXCR4 in human salivary gland cancers. Clin Exp Metastasis 30: 133-142, 2013.

30. Liang JJ, Zhu S, Bruggeman R, Zaino RJ, Evans DB, Fleming JB, Gomez HF, Zander DS and Wang H: High levels of expression of human stromal cell-derived factor-1 are associated with worse prognosis in patients with stage II pancreatic ductal adenocarcinoma. Cancer Epidemiol Biomarkers Prev 19: 2598-2604, 2010.

31. Torregrossa L, Giannini R, Borrelli N, Sensi E, Melillo RM, Leocata P, Materazzi G, Miccoli P, Santoro M and Basolo F: CXCR4 expression correlates with the degree of tumor infiltration and BRAF status in papillary thyroid carcinomas. Mod Pathol 25: 46-55, 2012. 